Jurnal Adat dan Budaya, Vol.1, No.1 Tahun 2019

ISSN: E-ISSN 2615-6156, P-ISSN: 2615-6113

Jurnal Homepage: https://ejournal.undiksha.ac.id/index.php/JABI/index

\title{
PENGARUH MODEL PEMBELAJARAN TAI BERBASIS NILAI TRI HITA KARANA TERHADAP SIKAP SOSIAL DAN KOMPETENSI PENGETAHUAN IPS KELAS V
}

\author{
Ni Made Selviyana Candra Dewi' ${ }^{1}$, Made Sumantri ${ }^{1}$, Ni Wayan Rati ${ }^{2}$ \\ 123Jurusan Pendidikan Dasar, Universitas Pendidikan Ganesha, Bali, Indonesia \\ E-mail: selviyana.candra.dewi@undiksha.ac.id
}

\begin{abstract}
Abstrak
Penelitian ini berawal dari permasalahan yang ada di Sekolah Dasar, berdasarkan observasi, wawancara dan studi dokumen yang dilakukan ditemukan bahwa partisipasi siswa dan daya tangkap siswa kurang dalam proses pembelajaran sehingga mengakibatkan rendahnya nilai kompetensi pengetahuan yang dimiliki siswa serta kurangnya adaptasi dan interaksi dalam proses pembelajaran yang mengakibatkan sikap sosial siswa dengan lingkungan sekitar masih tergolong rendah. Penelitian ini bertujuan untuk mengetahui pengaruh model pembelajaran Team Assisted Individualization (TAI) berbasis nilai Tri Hita Karana (THK) terhadap sikap sosial dan kompetensi pengetahuan IPS siswa kelas V SD Gugus I Kecamatan Sukasada Tahun Pelajaran 2018/2019. Jenis penelitian ini adalah quasi experiment dengan rancangan non-equivalent post-test only control group design. Populasi dalam penelitian ini berjumlah 215 siswa. Sampel penelitian ditentukan dengan teknik group random sampling yaitu SD Negeri 1 Pancasari sebagai kelas eksperimen berjumlah 33 siswa dan SD Negeri 3 Pancasari sebagai kelas kontrol berjumlah 38 siswa. Data penelitian dikumpulkan menggunakan metode non tes dan tes dengan instrumen lembar kuesioner untuk mengukur sikap sosial dan tes objektif untuk mengukur kompetensi pengetahuan IPS. Data yang diperoleh dianalisis dengan menggunakan statistik deskriptif dan statistik inferensial. Diketahui dari hasil analisis uji Manova diperoleh nilai signifikansi 0,000 lebih kecil dari taraf signifikansi 0,05. Artinya, model pembelajaran Team Assisted Individualization (TAI) berbasis nilai Tri Hita Karana (THK) memiliki pengaruh yang signifikan terhadap sikap sosial dan kompetensi pengetahuan IPS siswa kelas V SD Gugus I Kecamatan Sukasada Tahun Pelajaran 2018/2019.
\end{abstract}

Kata Kunci: TAI; THK; Sikap Sosial; Kompetensi Pengetahuan; IPS

\begin{abstract}
This research starts from the problems that exist in Elementary School, based on observations, interviews and document studies found that student participation and students ability to catch less in the learning process resulting in low values of competency knowledge possessed by students and lack of adaptation and interaction in the learning process that results in social attitudes of students the surrounding environment is still relatively low. This study aims to determine the effect of the Team Assisted Individualization (TAI) learning model based on the value of Tri Hita Karana (THK) on social attitudes and IPS knowledge competencies in class V SD Gugus I Sukasada District in Academic Year of 2018/2019. This type of research is quasi-experimental with nonequivalent post-test only control group design. The population in this study are 215 students. The research sample was determined by group random sampling technique Pancasari 1 Elementary School as an experimental class totaling 33 students and Pancasari Elementary School 3 as a control class totaling 38 students. The research data was collected using non-test methods and tests with questionnaire sheet instruments to measure social attitudes and objective tests to measure IPS knowledge competencies. The data obtained were analyzed using descriptive statistics and inferential statistics. It is known from the results of the Manova test analysis that the significance value of 0,000 is smaller than the significance level of 0.05 . This means that the Team Assisted Individualization (TAI) learning model based on the value of Tri Hita Karana (THK) has a significant influence on social attitudes and IPS knowledge competencies of fifth grade students of SD Gugus I Sukasada District in academic year of 2018/2019.
\end{abstract}

Keywords: TA; THK; Social Attitude; Knowledge Competence; Social Sciences 


\section{PENDAHULUAN}

Pendidikan memiliki peranan yang sangat penting dalam kehidupan manusia, baik manusia sebagai individu ataupun kelompok sebagai seorang warga negara yang baik dan bertanggung jawab. Pendidikan saat ini masih belum bisa dikatakan sebagai pendidikan yang berkualitas dan maju. Banyak pendidik yang masih menggunakan metode atau strategi yang masih sama dari tahun-tahun sebelumnya seperti ceramah, penugasan, dan tanya jawab yang diajukan oleh guru sedangkan pada tahun ini, proses pembelajaran sudah terpusat oleh siswa (Student Center). Banyak hal yang dapat mempengaruhi keberhasilan yang ingin dicapain dalam proses pembelajaran di dalam kelas, beberapa diantaranya yaitu strategi guru dalam mengajar yaitu dalam memvariasikan penggunaan model pembelajaran. Setiap guru menginginkan pembelajaran yang dilakukan bersama siswa dapat berjalan dengan baik sehingga siswa mempunyai pengetahuan, sikap dan keterampilan yang baik dan terus mengalami peningkatan terutama pada kompetensi Ilmu Pengetahuan Sosial (IPS) di Sekolah Dasar. IPS merupakan salah satu mata pelajaran yang kurang disenangi oleh siswa dikarenakan metode yang digunakan oleh guru tidak bervariasi sehingga siswa merasa bosan. Selain itu model yang digunakan juga tidak sesuai dengan perkembangan proses pembelajaran yang ada di SD saat ini.

Berdasarkan hasil wawancara bersama guru wali kelas $\mathrm{V}$ dan observasi pada proses pembelajaran IPS Kelas V yang dilakukan di SD Gugus I Kecamatan Sukasada Kabupaten Buleleng pada -7-9 Januari 2019, diperoleh hasil sebagai berikut. Pertama proses pembelajaran yang terjadi cenderung guru berperan lebih aktif dibandingkan dengan siswa. Kedua daya tangkap siswa kurang dan pengetahuan yang dimiliki siswa terbatas sehingga mengakibatkan rendahnya kompetensi pengetahuan yang dimiliki siswa. Ketiga kurangnya sarana dan prasarana seperti sumber buku. Dalam menyampaikan pembalajaran guru cenderung menggunakan buku pelajaran sebagai sumber belajar tanpa mencari sumber lain. Keempat kurangnya partisipasi dan kerjasama antar siswa dalam proses pembelajaran. Dalam kegiatan kelompok sangat jarang siswa mau bekerjasama dengan sepenuhnya. Sebagian besar hanya dilakukan oleh beberapa siswa atau bahkan hanya salah satu diantara beberapa siswa dalam kelompok tersebut sehingga tidak semua siswa aktif dan mengerti dalam pembahasan permasalahan yang diberikan oleh guru. Kelima sikap sosial siswa rendah, ada beberapa siswa yang suka menganggu teman, tidak mendengarkan perintah guru dan susah diberi tahu sehingga sering mengganggu teman lain yang sedang belajar. Keenam sebagian besar model yang digunakan dalam proses pembelajaran adalah model saintifik sehingga guru hanya berpatokan dengan model tersebut saja.

Berdasarkan permasalahan di atas, dapat diketahui bahwa kompetensi pengetahuan dalam mengikuti pembelajaran IPS cenderung pasif karena hanya menerima begitu saja penjelasan yang diberikan oleh guru dan sikap sosial siswa seperti perilaku siswa susah diatur dalam kegiatan kelompok sehingga dalam proses pembelajaran guru sedikit kesulitan serta kurangnya penanaman nilai-nilai sosial dalam proses belajar. Untuk mengatasi masalah tersebut banyak hal yang bisa dilakukan, seperti menggunakan berbagai model pembelajaran. Salah satu model pembelajaran yang dapat digunakan untuk mengatasi masalah rendahnya kompetensi pengetahuan IPS siswa adalah model pembelajaran Team Assisted Individualization. Dalam model pembelajaran TAI, "siswa ditempatkan dalam kelompok-kelompok kecil (4-5 siswa) yang heterogen dan selanjutnya diikuti dengan pemberian bantuan secara individu bagi siswa yang memerlukannya" (Shoimin, 2014:200). Suyitno (dalam Shoimin, 2014) menyatakan bahwa dengan pembelajaran kelompok, diharapkan para siswa dapat meningkatkan pikiran kritisnya, kreatif, dan menumbuhkan rasa sosial yang tinggi. Model Pembelajaran TAI dapat mengarahkan siswa untuk aktif baik dalam berdiskusi, tanya jawab, mencari jawaban, menjelaskan dan menyimak materi yang dijelaskan oleh temannya serta adanya interaksi sosial dalam kelompok. Model pembelajaran TAI sangat sesuai jika dipadukan dengan pembelajaran IPS karena memiliki tujuan yang sama yaitu pembelajaran IPS lebih menekankan pada sikap sosial siswa, siswa diharuskan untuk berkomunikasi dan berinteraksi dalam kelas dan dalam model pembelajaran TAI juga terdapat kerjasama antar anggota kelompok yang mengharuskan adanya interaksi dan komunikasi dalam proses pembelajaran untuk meningkatkan sikap sosial dan kompetensi pengetahuan siswa. Selain sikap sosial yang harus dimiliki antar siswa, kepedulian terhadap lingkungan sekitar juga harus diperhatikan agar suasana belajar menjadi nyaman dan harmonis. Sama halnya dengan tertanamnya nilai Tri Hita Karana pada diri manusia, yang berarti memiliki hubungan yang baik dengan sesama manusia, lingkungan dan Tuhan sang pencipta. Wirawan (2011) menyatakan bahwa dalam Tri Hita Karana terdapat tiga unsur yaitu hubungan manusia dengan Tuhan (prahyangan), hubungan manusia dengan sesama (pawongan) dan hubungan manusia dengan 
alam lingkungan (pelemahan). Maka dari itu, dalam proses pembelajaran harus menciptakan suasana yang harmonis dan menerapkan nilai-nilai yang terdapat dalam ajaran Tri Hita Karana agar kualitas pendidikan menjadi lebih optimal serta menjadikan pendidikan yang lebih baik lagi.

Berdasarkan uraian di atas, maka dilakukan penelitian untuk membuktikan adanya pengaruh model pembelajaran TAI berbasis nilai Tri Hita Karana terhadap sikap sosial dan kompetensi pengetahuan siswa. Dengan demikian, penelitian yang akan dilakukan berjudul "Pengaruh Model Pembelajaran TAI berbasis Nilai Tri Hita Karana Terhadap Sikap Sosial dan Kompetensi Pengetahuan IPS Kelas V".

Penelitian ini bertujuan untuk meningkatkan sikap sosial dan kompetensi pengetahuan IPS. Dalam dunia pendidikan, sikap menjadi salah satu hal yang sangat penting untuk dinilai agar peserta didik memiliki sikap yang baik, sopan, santun dan dapat menghargai satu sama lain pada lingkungannya. Suharyat (2009) menyatakan bahwa pengertian sikap dapat dipahami bahwa (1) sikap ditumbuhkan dan dipelajari sepanjang perkembangan orang yang bersangkutan dalam keterkaitannya dengan objek tertentu, (2) sikap merupakan hasil belajar manusia, sehingga sikap dapat ditumbuhkan dan dikembangkan melalui proses belajar, (3) sikap selalu berhubungan dengan objek, sehingga tidak berdiri sendiri, (4) sikap dapat berhubungan dengan satu objek, tetapi dapat pula berhubungan dengan sederet objek sejenis, (5) sikap memiliki hubungan dengan aspek motivasi dan perasaan atau emosi. Kompetensi dalam Kamus Besar Bahasa Indonesia diartikan sebagai "kecakapan dan kemampuan dalam menentukan atau memutuskan sesuatu" (Willy Susilo, dkk., 2018:74). Kemampuan kognitif adalah penampilan-penampilan yang dapat diamati sebagai hasil-hasil kegiatan atau proses memperoleh pengetahuan melalui pengalaman sendiri (Setiadi, 2016). Penentuan keberhasilan/kesuksesan siswa dapat dilihat melalui penilaian pengetahuan siswa (kognitif). Penilaian pengetahuan siswa merupakan pencapaian kompetensi dari siswa itu sendiri selama proses pembelajaran.

Pendidikan IPS sebagai "bidang studi yang diberikan pada jenjang pendidikan di lingkungan persekolahan, bukan hanya memberikan bekal pengetahuan saja, tetapi juga memberikan bekal nilai dan sikap serta keterampilan dalam kehidupan peserta didik, di masyarakat, bangsa dan Negara dalam berbagai karakteristik" (Susanto, 2013:144). Sehingga perlu adanya penerapan model pembelajaran yang tepat seperti model pembelajaran Team Assisted Individualization. Model Pembelajaran Team Assisted Individualization (TAI) merupakan salah satu tipe model pembelajaran kooperatif. Model pembelajaran kooperatif adalah "kegiatan pembelajaran dengan cara berkelompok untuk bekerja sama saling membantu mengkontruksi konsep, menyelesaikan persoalan, atau inkuiri" (Ngalimun, 2016:230). Dalam model pembelajaran kooperatif, siswa dilatih dan dibiasakan untuk saling membantu dan berbagi pengetahuan, pengalaman tugas dan tanggung jawab yang diberikan oleh guru serta dilatih untuk berinteraksi dan komunikasi. Model Team Assisted Individualization (TAI) memiliki dasar pemikiran yaitu "untuk mengadaptasi pembelajaran terhadap perbedaan individual berkaitan dengan kemampuan maupun pencapaian prestasi siswa" (Shoimin, 2014:200). Zubaedi (2011) berpendapat bahwa TAI merupakan metode pembelajaran kelompok dimana terdapat seseorang siswa yang lebih mampu berperan sebagai asisten yang bertugas membantu kelompok secara individual siswa lain yang kurang mampu dalam suatu kelompok. Model pembelajaran TAI akan memotivasi siswa untuk saling membantu anggota kelompoknya sehingga terjalinya interaksi dan komunikasi dalam kelompok. Berkaitan dengan model tersebut dalam pembelajaran IPS perlu adanya kombinasi agar pembelajaran tersebut menjadi lebih maksimal dengan berbasis nilai Tri Hita Karana. Dantes (2014) mengartikan dalam falsafah Tri Hita Karana dideskripsikan sebagai keyakinan dan kepercayaan manusia terhadap Tuhan (Hyang Prama Wisesa), hubungan dengan lingkungan alam dan hubungan manusia dengan sesamanya. Dengan adanya hubungan yang baik dengan tuhan, sesama manusia dan lingkungan akan menjadikan hubungan yang harmonis dan kesejahteraan khususnya pada pembelajaran IPS. Pada penerapan model TAI berbasis nilai Tri Hita Karana memiliki tujuan yang sama dengan pencapaian sikap sosial dan kompetensi pengetahuan IPS siswa.

\section{METODE}

Penelitian ini merupakan penelitian eksperimen karena mengungkapkan hubungan sebab dan akibat dengan cara melibatkan kelompok kontrol dan kelompok eksperimen. penelitian ini termasuk penelitian eksperimen semu (quasi experiment). Penelitian ini menggunakan rancangan non-equivalent post test only control group design. Penelitian ini terdiri dari tiga tahap yaitu tahap awal, pelaksanaan dan tahap akhir. 
Populasi dalam penelitian ini berjumlah 215 orang siswa. Sebelum menetapkan sampel terlebih dahulu dilakukan uji kesetaraan dengan menganalisis nilai kompetensi pengetahuan IPS menggunakan rumus Anava satu jalur. Berdasarkan hasil analisis diperoleh hasil bahwa signifikansi nilai kompetensi pengetahuan IPS pada populasi tersebut diperoleh $F$ hitung sebesar 1,01 jika dibandingkan dengan nilai $\mathrm{F}$ tabel maka $\mathrm{F}$ hitung $<\mathrm{F}$ Tabel $(1,01<2,05)$. Artinya nilai kompetensi pengetahuan IPS siswa kelas V SD Gugus I Kecamatan Suksada setara. Kemudian dilanjutkan dengan penentuan sampel dengan menggunakan teknik random sampling yaitu teknik undian. Berdasarkan pengundian diperoleh sampel yaitu SDN 1 Pancasari sebagai kelas eksperimen dan SDN 3 Pancasari sebagai kelas kontrol.

Dalam penelitian ini terdiri dari satu variabel bebas dan dua variabel terikat. Variabel bebas dalam penelitian ini adalah model pembelajaran TAI berbasis nilai Tri Hita Karana pada kelompok eksperimen dan pada kelompok kontrol tidak menggunakan model pembelajaran TAI berbasis nilai Tri Hita Karana, sedangkan variabel terikat dalam penelitian ini adalah sikap sosial dan kompetensi pengetahuan IPS.

Data yang dikumpulkan dalam penelitian ini yaitu sikap sosial dan kompetensi pengetahuan IPS siswa kelas V. Metode yang digunakan untuk mengumpulkan data yaitu tes dan non tes. Instrumen yang digunakan adalah tes pilihan ganda dan kuisioner. Untuk mengetahui kualitas isi, terlebih dahulu dilakukan uji validitas isi (uji pakar) yang dilakukan oleh dua pakar, guna mendapat kualitas tes yang baik setelah itu dilakasanakan uji coba instrument.

Hasil data yang diperoleh di analisis dengan menggunakan metode analisis deskriptif dan analisis inferensial. Metode analisis deskriptif berguna unutk mengetahui mean, median, modus, standar deviasi, dan varians data. Metode analisis inferensial yang digunakan adalah pada hipotesis 1 dan 2 menggunakan rumus Anava satu jalur dan hipotesis 3 menggunakan rumus Manova. Sebelum dilakukan perhitungan Anava satu jalur dan Manova terlebih dahulu dilakukan uji prasyarat yaitu uji normalitas, homogenitas, dan korelasi product moment. Perhitungan dilakukan dengan bantuan program SPSS 24 for windows.

\section{HASIL DAN PEMBAHASAN}

Berdasarkan hasil analisis data dengan analisis statistik deskriptif pada kelompok eksperimen dan kontrol, diperoleh deskripsi data sikap sosial kelompok eksperimen dan kelompok kontrol dapat dilihat pada tabel 1 berikut ini.

Tabel 1. Deskripsi Data Sikap Sosial

\begin{tabular}{lcc}
\hline \multicolumn{1}{c}{ Statistik Deskriptif } & Kelompok Eksperimen & Kelompok Kontrol \\
\hline Mean & 101,18 & 82,87 \\
\hline Median & 103,53 & 82,50 \\
\hline Modus & 105,5 & 84,97 \\
\hline Standar Deviasi & 6,61 & 6,38 \\
\hline Varians & 43,77 & 40,76 \\
\hline
\end{tabular}

Berdasarkan tabel 1 diketahui bahwa mean sikap sosial kelompok eksperimen yaitu 101,18 jika dikonversikan ke skala lima rata-rata sikap sosial berada pada kategori tinggi. Rata-rata kelompok kontrol yaitu 82,87 jika dikonversikan ke skala lima rata-rata sikap sosial berada pada kategori sedang.

Selain deskripsi data tersebut berikut ini merupakan hasil analisis statistik deskriptif data sikap sosial kelompok eksperimen dan kontrol. Deskripsi data sikap sosial dapat dilihat pada tabel 2 berikut ini.

Tabel 2. Deskripsi Data Kompetensi Pengetahuan IPS

\begin{tabular}{lcc}
\hline \multicolumn{1}{c}{ Statistik Deskriptif } & Kelompok Eksperimen & Kelompok Kontrol \\
\hline Mean & 19,30 & 16,08 \\
\hline Median & 20,00 & 16,00 \\
\hline Modus & 21,5 & 15,3 \\
\hline Standar Deviasi & 3,21 & 3,23 \\
\hline
\end{tabular}


Berdasarkan tabel 2 diketahui bahwa mean kompetensi pengetahuan IPS kelompok eksperimen yaitu 19, 30, jika dikonversikan ke skala lima rata-rata kompetensi pengetahuan IPS berada pada kategori tinggi. Rata-rata kelompok kontrol yaitu 16,08 jika dikonversikan ke skala lima rata-rata kompetensi pengetahuan IPS berada pada kategori sedang.

Sebelum melakukan uji hipotesis terlebih dahulu dilakukan uji prasyarat analisis yaitu uji normalitas, uji homogenitas, dan uji korelasi product moment.

Ringkasan hasil uji normalitas data sikap sosial dan kompetensi pengetahuan IPS kelompok eksperimen dan kontrol dapat dilihat pada tabel 3 berikut ini.

Tabel 3. Ringkasan Uji Normalitas Data Sikap Sosial dan Kompetensi Pengetahuan IPS Tests of Normality

\begin{tabular}{|c|c|c|c|c|c|c|}
\hline & \multicolumn{3}{|c|}{ Kolmogorov-Smirnova } & \multicolumn{3}{|c|}{ Shapiro-Wilk } \\
\hline & Statistic & Df & Sig. & Statistic & $\mathrm{df}$ & Sig. \\
\hline Sikap Sosial Eksperimen & .123 & 33 & .200 & .953 & 33 & .159 \\
\hline Sikap Sosial Kontrol & .071 & 38 & .200 & .966 & 38 & .300 \\
\hline $\begin{array}{l}\text { Kompetensi Pengetahuan } \\
\text { IPS Eksperimen }\end{array}$ & .125 & 33 & .200 & .951 & 33 & .142 \\
\hline $\begin{array}{ll}\text { Kompetensi } & \text { Pengetahuan } \\
\text { IPS Kontrol } & \\
\end{array}$ & .093 & 38 & .200 & .959 & 38 & .170 \\
\hline
\end{tabular}

a. Lilliefors Significance Correction

Berdasarkan hasil uji normalitas menggunakan Kolmogorov-Smirnov dan Shapiro-Wilk sesuai dengan tabel 3, hasil analisis menunjukkan bahwa keseluruhan nilai signifikansi dari perhitungan Kolmogorov-Smirnov dan Shapiro-Wilk lebih tinggi dari 0,050. Dari hasil tersebut dapat disimpulkan bahwa data sikap sosial dan kompetensi pengetahuan IPS berdistribusi normal.

Setelah dilakukan uji normalitas sebaran data, data sikap sosial dan kompetensi pengetahuan IPS kemudian diuji homogenitasnya. Ringkasan hasil uji homogenitas data sikap sosial dan kompetensi pengetahuan IPS kelompok eksperimen dan kontrol dapat dilihat pada tabel 4 berikut ini.

Tabel 4. Ringkasan Uji Homogenitas Data Sikap Sosial dan Kompetensi Pengetahuan IPS

\begin{tabular}{ccccc}
\hline \multicolumn{5}{c}{ Test of Homogeneity of Variances } \\
\hline & Levene Statistic & df1 & df2 & Sig. \\
\hline Sikap Sosial & .096 & 1 & 69 & .758 \\
\hline Kompetensi Pengetahuan IPS & .014 & 1 & 69 & .907 \\
\hline
\end{tabular}

Dengan uji homogenitas menggunakan Levene's Test of Equality of Error Varians sesuai dengan tabel 4, hasil analisis menunjukkan bahwa keseluruhan nilai signifikansi dari perhitungan korelasi product moment lebih lebih tinggi dari 0,050. Dari hasil tersebut dapat disimpulkan bahwa data sikap sosial dan kompetensi pengetahuan IPS bersifat homogen.

Setelah dilakukan uji homogenitas kemudian dilakukan uji korelasi product moment untuk mengetahui apakah terdapat korelasi terhadap variabel terikat. Ringkasan hasil uji korelasi product moment data sikap sosial dan kompetensi pengetahuan IPS kelompok eksperimen dan kontrol dapat dilihat pada tabel 5 dan tabel 6 berikut ini.

Tabel 5. Ringkasan Uji Korelasi Product Moment Kelompok Eksperimen

\begin{tabular}{llcc}
\hline & \multicolumn{2}{c}{ Correlations } & \\
\hline \multirow{2}{*}{ Sikap Sosial } & Searson Correlation & Sikap Sosial & $\begin{array}{c}\text { Kompetensi } \\
\text { Pengetahuan IPS }\end{array}$ \\
\cline { 2 - 4 } & Sig. (2-tailed) & 1 & .044 \\
\cline { 2 - 4 } & $\mathrm{N}$ & 33 & .809 \\
\hline \multirow{2}{*}{ KPS } & Pearson Correlation & .044 & 33 \\
\cline { 2 - 4 } & Sig. (2-tailed) & .809 & 1 \\
\hline
\end{tabular}


Tabel 6. Ringkasan Uji Korelasi Product Moment Kelompok Kontrol

\begin{tabular}{|c|c|c|c|}
\hline \multicolumn{4}{|c|}{ Correlations } \\
\hline & & Sikap Sosial & $\begin{array}{c}\text { Kompetensi } \\
\text { Pengetahuan IPS }\end{array}$ \\
\hline \multirow[t]{3}{*}{ Sikap Sosial } & Pearson Correlation & 1 & .004 \\
\hline & Sig. (2-tailed) & & .979 \\
\hline & $\mathrm{N}$ & 38 & 38 \\
\hline \multirow[t]{3}{*}{ Kompetensi Pengetahuan } & Pearson Correlation & .004 & 1 \\
\hline & Sig. (2-tailed) & .979 & \\
\hline & $\mathrm{N}$ & 38 & 38 \\
\hline
\end{tabular}

Dengan uji korelasi product moment sesuai dengan tabel, hasil analisis menunjukkan bahwa keseluruhan nilai signifikansi dari perhitungan lebih lebih tinggi dari 0,050. Dari hasil tersebut dapat disimpulkan bahwa data sikap sosial dan kompetensi pengetahuan IPS baik kelompok eksperimen dan kelompok kontrol tidak berkorelasi.

Berdasarkan pengujian asumsi, diperoleh hasil data berdistribusi normal, bersifat homogeny, dan tidak terdapat korelasi. Analisis dilanjutkan dengan pengujian hipotesis. Dalam penelitian ini terdapat 3 hipotesis. Hipotesis 1 menggunakan rumus Anava satu jalur untuk mengetahui apakah terdapat pengaruh model pembelajaran TAI berbasis Tri Hita Karana terhadap sikap sosial siswa. Perhitungan uji hipotesis 1 satu menggunakan bantuan SPSS 24 for windows. Hasil uji hipotesis 1 dapat dilihat pada tabel 7 dan 8 berikut ini

Tabel 7. Descriptives Hasil Uji Hipotesis 1

\begin{tabular}{|c|c|c|c|c|c|c|c|c|}
\hline \multicolumn{9}{|c|}{ Descriptives } \\
\hline \multicolumn{9}{|l|}{ Sikap Sosial } \\
\hline & \multirow[b]{2}{*}{$\mathrm{N}$} & \multirow[t]{2}{*}{ Mean } & \multirow[t]{2}{*}{$\begin{array}{c}\text { Std. } \\
\text { Deviation }\end{array}$} & \multirow[t]{2}{*}{$\begin{array}{l}\text { Std. } \\
\text { Error }\end{array}$} & \multicolumn{2}{|c|}{$\begin{array}{l}\text { 95\% Confidence } \\
\text { Interval for Mean }\end{array}$} & \multirow[t]{2}{*}{$\begin{array}{l}\text { Minim } \\
\text { um }\end{array}$} & \multirow[t]{2}{*}{$\begin{array}{l}\text { Maxim } \\
\text { um }\end{array}$} \\
\hline & & & & & $\begin{array}{l}\text { Lower } \\
\text { Bound }\end{array}$ & $\begin{array}{l}\text { Upper } \\
\text { Bound }\end{array}$ & & \\
\hline Eksperimen & 33 & 101.18 & 6.617 & 1.152 & 98.84 & 103.53 & 88 & 111 \\
\hline Kontrol & 38 & 82.87 & 6.385 & 1.036 & 80.77 & 84.97 & 72 & 95 \\
\hline Total & 71 & 91.38 & 11.233 & 1.333 & 88.72 & 94.04 & 72 & 111 \\
\hline
\end{tabular}

Tabel 8. Analisis Anava A Hipoteses 1

\begin{tabular}{lccccr}
\hline \multicolumn{7}{c}{ ANOVA } \\
\hline Sikap Sosial & \multicolumn{7}{c}{ Sig. } \\
\hline Sum of Squares & df & Mean Square & F & S \\
\hline Between Groups & 5923.481 & 1 & 5923.481 & 140.490 & .000 \\
\hline Within Groups & 2909.251 & 69 & 42.163 & & \\
\hline Total & 8832.732 & 70 & & \\
\hline
\end{tabular}

Berdasarkan tabel 8 hasil perhitungan Anava satu jalur data Berdasarkan Tabel 8 hasil perhitungan Anava satu jalur data kompetensi pengetahuan IPS siswa pada hipotesis dua diperoleh nilai $\mathrm{F}$ sebesar 17,650 dengan signifikansi dibawah $5 \%$ yaitu $0,000(0,000<0,05)$. Sehingga $\mathrm{H}_{0}$ ditolak dan $\mathrm{H}_{1}$ diterima, dapat disimpulkan bahwa terdapat pengaruh model pembelajaran Team Assisted Individualization (TAI) berbasis nilai Tri Hita Karana terhadap kompetensi pengetahuan IPS siswa kelas V SD Gugus I Kecamatan Sukasada Tahun Pelajaran 2018/2019. Perhitungan 
analisis hipotesis 2 menggunakan bantuan SPSS 24 for windows. Hasil perhitungan hipotesis 2 dapat dilihat pada tabel 9 dan 10 berikut ini.

Tabel 9. Descriptives Hasil Uji Hipotesis 2

\section{Descriptives}

Kompetensi Pengetahuan IPS

95\% Confidence Interval for

Std. Std. Mean

N Mean Deviation Error Lower Bound Upper Bound Minimum Maximum

\begin{tabular}{lllllllll} 
Eksperimen & 33 & 19.30 & 3.216 & .560 & 18.16 & 20.44 & 13 & 24 \\
\hline Kontrol & 38 & 16.08 & 3.233 & .524 & 15.02 & 17.14 & 11 & 22 \\
\hline Total & 71 & 17.58 & 3.588 & .426 & 16.73 & 18.43 & 11 & 24 \\
\hline
\end{tabular}

Tabel 10. Analisis Anava A Hipotesis 2

\begin{tabular}{lccccc}
\hline \multicolumn{7}{c}{ ANOVA } \\
\hline Kompetensi Pengetahuan IPS & \multicolumn{7}{c}{} & & \\
\hline & Sum of Squares & df & Mean Square & F & Sig. \\
\hline Between Groups & 183.591 & 1 & 183.591 & 17.650 & .000 \\
\hline Within Groups & 717.733 & 69 & 10.402 & & \\
\hline Total & 901.324 & 70 & & & \\
\hline
\end{tabular}

Berdasarkan tabel 10 hasil perhitungan Anava satu jalur data kompetensi pengetahuan IPS siswa pada hipotesis dua diperoleh nilai $\mathrm{F}$ sebesar 17,650 dengan signifikansi dibawah $5 \%$ yaitu $0,000(0,000<0,05)$. Sehingga $\mathrm{H}_{0}$ ditolak dan $\mathrm{H}_{1}$ diterima, dapat disimpulkan bahwa terdapat pengaruh model pembelajaran Team Assisted Individualization (TAI) berbasis nilai Tri Hita Karana terhadap kompetensi pengetahuan IPS siswa kelas V SD Gugus I Kecamatan Sukasada Tahun Pelajaran 2018/2019.

Perhitungan analisis hipotesis 3 menggunakan bantuan SPSS 24 for windows. Hasil perhitungan hipotesis 3 dapat dilihat pada tabel 11 berikut ini. 
Tabel 11. Hasil Uji Hipotesis 3

\begin{tabular}{llccccc}
\hline \multicolumn{7}{c}{ Multivariate Tests } \\
\hline Effect & \multicolumn{7}{c}{ Value } & $\mathrm{F}$ & Hypothesis df & Error df & Sig. \\
\hline \multirow{2}{*}{ Intercept } & Pillai's Trace & .996 & $8141.243^{\mathrm{b}}$ & 2.000 & 68.000 & .000 \\
\cline { 2 - 7 } & Wilks' Lambda & .004 & $8141.243^{\mathrm{b}}$ & 2.000 & 68.000 & .000 \\
\cline { 2 - 7 } & Hotelling's Trace & 239.448 & $8141.243^{\mathrm{b}}$ & 2.000 & 68.000 & .000 \\
\cline { 2 - 7 } & Roy's Largest Root & 239.448 & $8141.243^{\mathrm{b}}$ & 2.000 & 68.000 & .000 \\
\hline Kelompok & Pillai's Trace & .699 & $78.848^{\mathrm{b}}$ & 2.000 & 68.000 & .000 \\
\cline { 2 - 7 } & Wilks' Lambda & .301 & $78.848^{\mathrm{b}}$ & 2.000 & 68.000 & .000 \\
\cline { 2 - 7 } & Hotelling's Trace & 2.319 & $78.848^{\mathrm{b}}$ & 2.000 & 68.000 & .000 \\
\cline { 2 - 7 } & Roy's Largest Root & 2.319 & $78.848^{\mathrm{b}}$ & 2.000 & 68.000 & .000 \\
\hline a. Design: Intercept + Kelompok \\
\hline \multicolumn{7}{l}{ b. Exact statistic }
\end{tabular}

Berdasarkan tabel 11 hasil perhitungan Manova, nilai F Pillai's Trace, Wilks' Lambda, Hotel;ing Trace, Roy's Largest Root adalah 78,848 seluruhnya memiliki signifikansi 0,000 dan lebih kecil dari $0,05(0,000<0,05)$, sehingga $\mathrm{H}_{0}$ ditolak dan $\mathrm{H}_{1}$ diterima. Hal ini berarti bahwa terdapat pengaruh model pembelajaran Team Assisted Individualization (TAI) berbasis nilai Tri Hita Karana terhadap Sikap Sosial dan Kompetensi Pengetahuan IPS pada siswa kelas V SD Gugus I Kecamatan Sukasada Tahun Pelajaran 2018/2019.

Pembelajaran dengan model Team Assisted Individualization ini, dimulai dari pemberian tes awal untuk mengetahui kekurangan siswa terlebih dahulu kemudian melalui pembentukan kelompok yang heterogen siswa dapat berdiskusi lebih banyak dan berpikir bersama dalam menyelesaikan masalah. Persoalan masalah atau pemberian tugas dijelaskan oleh guru, siswa diberikan tanggung jawab penuh dan bergantung kepada hasil kerja kelompok serta keberhasilan setiap siswa ditentukan oleh keberhasilan kelompoknya sehingga dalam kegiatan ini seluruh siswa dapat aktif dan bekerja sama, jika ada siswa yang belum paham tentang materi dapat bertanya dengan anggota lain atau siswa yang memiliki akademik bagus. Setelah kegiatan, siswa diberikan tes akhir untuk menentukan kemampuan yang dimiliki setelah proses belajar kelompok yang sudah dilaksanakan. Dilanjutkan dengan pemberian skor yang dapat meningkatkan motivasi dan semangat dalam belajar. Kemudian guru menyajikan kembali materi yang sudah dibahas guna mengingatkan kembali pelajaran yang sudah didapatkan oleh siswa. Dari penelitian yang sudah dilaksanakan ditemukan bahwa dengan menggunakan model pembelajaran Team Assisted Individualization dapat meningkatkan aktifitas siswa menjadi lebih aktif dalam proses belajar dan dapat memecahkan masalah bersama dengan berdiskusi kelompok sehingga dapat meningkatkan kompetensi pengetahuan IPS siswa. Hal tersebut juga diperkuat oleh penelitian yang dilakukan oleh Made Sukma Hadinata (2013) yang menunjukan bahwa terdapat perbedaan prestasi belajar IPS antara siswa yang dibelajarkan model pembelajaran Team Assisted Individualization (TAI) dengan siswa yang tidak dibelajarkan menggunakan model pembelajaran Team Assisted Individualization (TAI) terhadap prestasi belajar IPS siswa kelas IV SD Gugus IV Kecamatan Tejakula Kabupaten Buleleng. Dijelaskan bahwa siswa yang dibelajarkan menggunakan model Team Assisted Individualization ini siswa akan lebih banyak berdiskusi dan berpikir bersama dalam menyelesaikan persoalan-persoalan IPS sehingga dapat meningkatkan prestasi belajar IPS siswa.

Dengan berbasis nilai Tri Hita Karana dalam model pembelajaran ini, dapat meningkatkan sikap sosial yang dimiliki siswa. Hal ini dikarenakan dalam proses pembelajaran dengan menerapkan nilai yang terkandung dalam Tri Hita Karana menjadikan proses belajar yang harmonis dan saling peduli satu sama lain. Kegiatan yang dilakukan sebelum memulai pembelajaran dan sesudah proses pembelajaran siswa berdoa dengan keyakinan terhadap Tuhan menjadikan proses pembelajaran menjadi lancar, selanjutnya hubungan yang baik dengan sesama dapat menumbuhkan rasa peduli dan menghormati perbedaan satu sama lain serta terjadinya interaksi yang baik khususnya dalam kegiatan kelompok. Sebelum dan sesudah selesai pembelajaran siswa memperhatikan lingkungan sekitar 
sebagai rasa peduli terhadap kebersihan kelas agar nyaman dalam proses pembelajaran sehingga dengan menerapkan model pembelajaran Team Assisted Individualization berbasis nilai Tri Hita Karana akan meningkatkan kualitas siswa baik sikap maupun pengetahuan siswa. Dengan kata lain, model pembelajaran pembelajaran Team Assisted Individualization berbasis nilai Tri Hita Karana mempunyai pengaruh besar yang signifikan terhadap sikap sosial dan kompetensi pengetahuan IPS siswa. Selain itu, Hasil penelitian yang dilakukan oleh Luh Dewi Puspawati (2017) hasil penelitian menemukan terdapat perbedaan yang signifikan kompetensi pengetahuan IPS kelompok eksperimen dan kelompok control. Hal ini terjadi karena perbedaan pemberian treatment yang diberikan saat pembelajaran. Kelompok eksperimen diberikan pembelajaran dengan menerapkan model pembelajaran kooperatif tipe Team Assisted Individualization (TAI) berbantuan peta konsep memiliki nilai rata-rata yang lebih tinggi dibandingkan dengan siswa dikelompok kontrol yang tidak dibelajarkan menggunakan model pembelajaran kooperatif tipe Team Assisted Individualization (TAI) berbantuan peta konsep.

Dapat disimpulkan dengan adanya kegiatan kelompok siswa dapat berinteraksi lebih aktif, mampu mendapatkan informasi lebih banyak dan saling bekerja sama serta dapat memecahkan masalah lebih mudah dibandingkan dengan kegiatan individu. Hal ini diperkuat juga dengan pendapat Zubaedi (2011) menyatakan bahwa dari hasil kerja sama dengan teman atau berkelompok akan memberikan hasil belajar lebih tinggi daripada kompetensi, khususnya siswa yang berkemampuan rendah. Sehingga dengan berkelompok, siswa mampu meningkatkan hasil belajar maupun pengetahuan yang dimiliki siswa menjadi lebih tinggi. Selain itu dalam berkelompok harus ada interaksi dan komunikasi yang berkaitan dengan hubungan manusia dengan sesama (Pawongan) dalam ajaran Tri Hita Karana. Sehingga dalam kegiatan kelompok dan Tri Hita Karana saling berkaitan dan dapat meningkatkan sikap sosial siswa menjadi lebih baik.

Berdasarkan temuan-temuan yang ada pada penelitian ini dapat dinyatakan bahwa sikap sosial siswa meningkat setelah mengikut model pembelajaran Team Assisted Individualization berbasis nilai Tri Hita Karana, begitu juga dengan kompetensi pengetahuan IPS siswa meningkat setelah mengikuti model pembelajaran Team Assisted Individualization berbasis nilai Tri Hita Karana. Hal ini menunjukkan terdapat pengaruh yang signifikan model pembelajaran Team Assisted Individualization berbasis nilai Tri Hita Karana terhadap sikap sosial dan kompetensi pengetahuan IPS pada siswa kelas V di gugus I Kecamatan Sukasada tahun pelajaran 2018/2019.

\section{SIMPULAN DAN SARAN}

Berdasarkan hasil pengujian hipotesis dan pembahasan hasil penelitian, maka simpulan dari penelitian ini adalah 1) terdapat pengaruh model pembelajaran Team Assisted Individualization berbasis nilai Tri Hita Karana terhadap sikap sosial Kelas V SD Gugus I Kecamatan Sukasada Tahun Pelajaran 2018/2019, hal tersebut diperoleh dari uji analisis Anava A antara siswa yang mengikuti model pembelajaran Team Assisted Individualization berbasis nilai Tri Hita Karana dengan siswa yang tidak mengikuti model pembelajaran Team Assisted Individualization berbasis nilai Tri Hita Karana memperoleh hasil signfikansi 0,000 $<0,05$. 2) terdapat pengaruh model pembelajaran Team Assisted Individualization berbasis nilai Tri Hita Karana terhadap sikap sosial Kelas V SD Gugus I Kecamatan Sukasada Tahun Pelajaran 2018/2019. Hal ini diperoleh dari uji analisis Anava A memperoleh hasil signfikansi 0,000 $<0,05$. 3) terdapat pengaruh model pembelajaran Team Assisted Individualization berbasis nilai Tri Hita Karana terhadap sikap sosial dan kompetensi pengetahuan IPS dengan siswa yang tidak mengikuti model pembelajaran Team Assisted Individualization berbasis nilai Tri Hita Karana memperoleh hasil analisis, nilai F Pillai's Trace, Wilks' Lambda, Hotel;ing Trace, Roy's Largest Root adalah 78.848 seluruhnya memiliki signifikansi 0,000 dan lebih kecil dari 0,05 $(0,000<0,05)$.

Berdasarkan pemaparan pemaparan di atas dapat disimpulkan bahwa terdapat pengaruh model pembelajaran Team Assisted Individualization berbasis nilai Tri Hita Karana terhadap sikap sosial dan kompetensi pengetahuan IPS siswa kelas V SD Gugus I Kecamatan Suksada tahun pelajaran 2018/2019.

Dengan demikian penerapan model pembelajaran Team Assisted Individualization (TAI) berbasis nilai Tri Hita Karana pengaruh positif terhadap sikap sosial dan kompetensi pengetahuan IPS siswa kelas V SD Gugus I Kecamatan Sukasada Tahun Pelajaran 2018/2019. 
Berdasarkan temuan-temuan dalam penelitian ini, dapat disampaikan saran-saran sebagai berikut, 1) Kepada Siswa, Siswa-siswa di SD agar lebih aktif dalam mengikuti pembelajaran dan terus mengembangkan pemahamannya dengan membangun sendiri pengetahuan tersebut melalui pengalaman. 2) Kepada Guru, Guru IPS SD agar lebih inovatif dalam memilih model pembelajaran dan media pembelajaran yang akan diterapkan pada proses pembelajaran. Sehingga pembelajaran lebih efektif dan menarik, tidak monoton, serta dapat meningkatkan sikap sosial dan kompetensi pengetahuan siswa. 3) Kepada Kepala Sekolah, Kepala Sekolah disarankan agar dapat menciptakan kondisi yang mampu mendorong para guru untuk mencoba menerapkan model pembelajaran Team Assisted Individualization (TAI) berbasis nilai Tri Hita Karana dalam pembelajaran IPS khususnya dan mata pelajaran lain pada umumnya dalam upaya meningkatkan sikap sosial dan kompetensi pengetahuan IPS siswa. 4) Kepada Peneliti Lain, Peneliti yang berminat untuk mengadakan penelitian lebih lanjut tentang model pembelajaran Team Assisted Individualization (TAI) berbasis nilai Tri Hita Karana dalam bidang ilmu lainnya. Penelitian ini sebagai bahan pertimbangan untuk perbaikan dan penyempurnaan penelitian yang akan dilaksanakan.

\section{DAFTAR PUSTAKA}

Dantes, Nyoman. 2014. Landasan Pendidikan Tinjauan Dari Dimensi Makropedagogis. Singaraja: Graha Ilmu.

Hadinata, Md Sukma, dkk. 2013. "Pengaruh Model Pembelajaran Team Asissted Individualization (TAI) Terhadap Prestasi Belajar IPS Kelas IV SD Gugus IV Bondalem Kecamatan Tejakula". Jurnal Mimbar PGSD Universitas Pendidikan Ganesha. Vol. 1, No. 1.

Ngalimun. 2016. Strategi dan Model Pembelajaran. Yogyakarta: Aswaja Pressindo.

Puspawati, Luh Dewi, dkk. 2017. "Pengaruh Model Pembelajaran Kooperatif Tipe Team Assisted Individualization berbantuan peta konsep terhadap Kompetensi Pengetahuan IPS Siswa Kelas V SD Gugus Raden Ajeng Kartini Denpasar Barat". Jurnal Mimbar PGSD Universitas Pendidikan Ganesha. Vol. 5, No. 2.

Setiadi, Hari. 2016. "Pelaksanaan Penilaian Pada Kurikulum 2013". Jurnal Penelitian dan Evaluasi Pendidikan. Vol. 20, No. 2.

Shoimin, Aris. 2014. 68 Model Pembelajaran Inovatif dalam Kurikulum 2013. Yogyakarta: Ar Ruzz Media.

Suharyat, Yayat. 2009. "Hubungan Antara Sikap, Minat dan Perilaku Manusia". Tersedia pada https://s3.amazonaws.com/academia.edu.documents. Diakses, 27 Maret 2019.

Susanto. Ahmad. 3013. Teori Belajar \& Pembelajaran di Sekolah Dasar. Jakarta: Kencana Prenada Media Group.

Susilo, Willy., dkk. 2018. Sistem Kompetensi Nasional Berbasis KKNI \& SKKNI. Yogyakarta: CV Andi Offset.

Wirawan, I M. A. 2011. Tri Hita Karana: Kajian Teologi, Sosiologi dan Ekologi Menurut Veda. Surabaya: Paramita.

Zubaedi. 2011. Desain Pendidikan Karakter Konsepsi dan Aplikasinya dalam Lembaga Pendidikan. Jakarta: Kencana Prenada Media Group. 